\title{
Gas Chromatographic Studies of Oxide and Hydroxide Species of Tungsten - Model Experiments with Respect to the Physico-Chemical Characterization of Seaborgium (Element 106)
}

\author{
By A. Vahle ${ }^{1}$, S. Hübener ${ }^{1}$, H. Funke ${ }^{1,2}$, B. Eichler ${ }^{3}$, D. T. Jost ${ }^{3}$, A. Türler ${ }^{3}$, W. Brüchle ${ }^{4}$ and E. Jäger $^{4}$ \\ 1 Forschungszentrum Rossendorf e.V., Institut für Radiochemie, D-01314 Dresden, Germany \\ 2 European Synchrotron Radiation Facility, F-38043 Grenoble Cedex, France \\ 3 Paul Scherrer Institut, Labor für Radio- und Umweltchemie, CH-5232 Villigen, Switzerland \\ 4 Gesellschaft für Schwerionenforschung, Planckstr. 1, D-64291 Darmstadt, Germany
}

(Received July 3, 1998; accepted in revised form December 1, 1998)

Gas chromatography / Reaction gas chromatography / Tungsten oxide / Tungsten hydroxide / Adsorption

\begin{abstract}
Summary
The adsorption/desorption behavior of carrier-free $W$ on quartzglass surfaces in dry and moist oxygen was studied by off-line thermochromatography in the temperature range $330-1480 \mathrm{~K}$. In dry oxygen $W$ could not be volatilized. In moist oxygen the deposition temperature varies significantly with the humidity of the carrier-gas. The transport can be described by $\mathrm{WO}_{2}(\mathrm{OH})_{2(\mathrm{~g})}$ $\rightleftarrows \mathrm{WO}_{3(\mathrm{ads})}+\mathrm{H}_{2} \mathrm{O}_{(\mathrm{g})}$ analogous to the lighter homologue Mo. Evaluation of the experimental data was carried out by means of the new computer code TECPROF which allows to consider real temperature profiles.

$\mathrm{Up}$ to an admixture of $60 \mu \mathrm{g} \mathrm{MoO}_{3}$-carrier the formation of heteropolynuclear complexes was not observed. However, the W was deposited at higher temperatures compared to experiments without a homologous carrier. Isothermal on-line gas chromatography experiments were carried out with short-lived $W$ isotopes to model future $\mathrm{Sg}$ experiments and to optimize the experimental conditions.
\end{abstract}

\section{Introduction}

The element 106 , seaborgium $(\mathrm{Sg})$, is available only in quantities of short-lived, single atoms like all transactinide elements. Fast methods which guarantee a high yield at a high selectivity are needed for the chemical characterization of this class of elements.

Gas chromatography of oxychlorides in quartzglass columns has already been applied successfully to study seaborgium [1]. Alternatively we chose the $\mathrm{O}_{2}$ $\mathrm{H}_{2} \mathrm{O}_{(\mathrm{g}} / \mathrm{SiO}_{2(\mathrm{~s})}$-system for the physico-chemical characterization of seaborgium by gas-chromatographic techniques.

To characterize a transactinide element its chemical properties have to be compared with those of other elements, first of all its supposed lighter homologues. The chemical behavior of trace amounts of the elements considered for this comparison is often known only incompletely and must be studied under the same conditions as the transactinide element. On the other hand in preparatory experiments the homologues can be used to model the transactinides.

The behavior of trace amounts of molybdenum as a homologue of seaborgium in the system oxygen-wa- ter vapor/quartz-glass has been already studied earlier by off-line thermochromatography [2] and high-temperature on-line isothermal gas chromatography [3]. Molybdenum was found to be transported via reaction gas chromatography governed by the basic reactions dissociative adsorption and associative desorption: $\mathrm{MoO}_{2}(\mathrm{OH})_{2(\mathrm{~g})} \rightleftarrows \mathrm{MoO}_{3(\mathrm{ads})}+\mathrm{H}_{2} \mathrm{O}_{(\mathrm{g})}$. The enthalpy of dissociative adsorption was determined to be

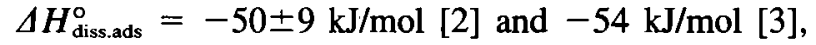
respectively. The studied chemical system seemed to be well-suited for a chemical characterization of seaborgium, especially on account of the high selectivity to heavy actinides and the lighter transactinides rutherfordium ( $\mathrm{Rf}$ ) and dubnium $(\mathrm{Db})$.

However, in contrast to the gas chromatography of oxychlorides the reaction gas chromatography of group 6 elements in the $\mathrm{O}_{2}-\mathrm{H}_{2} \mathrm{O}_{(\mathrm{g})} / \mathrm{SiO}_{2(\mathrm{~s})}$-system is characterized by relatively slow kinetics making it difficult to achieve over all retention times in the order of magnitude of the half-life of ${ }^{266} \mathrm{Sg}\left(t_{1 / 2}=21 \mathrm{~s}\right.$ [4]) or ${ }^{265} \mathrm{Sg}\left(t_{1 / 2}=7.4 \mathrm{~s} \mathrm{[4])}\right.$.

In this work, as a further step towards the characterization of seaborgium in the $\mathrm{O}_{2}-\mathrm{H}_{2} \mathrm{O}_{(\mathrm{g})} / \mathrm{SiO}_{2(\mathrm{~s})}$-system the behavior of tungsten in this system was studied. According to semi-empirical calculations of sublimation enthalpies for the transition elements [5] and extrapolations within group 6 in this system $[6,7]$ seaborgium should resemble mostly tungsten. Tungsten was studied by off-line thermochromatography and on-line isothermal gas chromatography to establish optimum experimental conditions for studying seaborgium and to determine thermodynamical state functions useful for the evaluation and interpretation of future seaborgium experiments.

\section{General considerations}

\subsection{High-temperature chemistry of oxide} and hydroxide species of tungsten

Mo and $\mathrm{W}$ behave very similar due to the only slightly different ionic radii. However, the stability of the highest oxidation state increases from Mo to $\mathrm{W}$ and $\mathrm{W}$ 
compounds are mostly less volatile than the corresponding Mo compounds.

W forms many stable oxides. In an excess of oxygen $\mathrm{WO}_{3}$ should be the main component, which sublimates below its melting point $(1745 \mathrm{~K})$. In the gaseous phase over $\mathrm{WO}_{3}$ the polymers $\left(\mathrm{WO}_{3}\right)_{n}(n=2-4)$ have been identified with the trimer and the tetramer as the major species analogous to Mo. Below the boiling point of $\mathrm{WO}_{3}(2215 \mathrm{~K})$ the gaseous monomer was observed only in negligible amounts [8]. However, in contrast to this predominant formation of polymers for macroamounts, short-lived, carrier-free $\mathrm{W}$ isotopes at concentrations excluding a collision of two or more molecules can only be volatilized as monomeric $\mathrm{WO}_{3}$ in dry oxygen.

In moist oxygen species such as $\mathrm{WO}_{2}(\mathrm{OH})_{2}$ can be formed which should be more volatile than $\mathrm{WO}_{3}$ [9-13].

Thermodynamic data for $\mathrm{W}$, its oxides and hydroxides are compiled in Table 1.

\subsection{High-temperature gas chromatography of oxide and hydroxide species of carrier-free tungsten}

The fundamental processes governing gas adsorption chromatography change essentially at the transition from macroscopic to trace amounts $\left(\approx 10^{12}\right.$ particles/ $\mathrm{cm}^{3}$ ). In case of macroscopic amounts the column surface is covered by a condensed phase and chromatography is a multiple sublimation-desublimation process. Trace amounts cannot be characterized as pure condensed phases nor can they form extended monolayers on an adsorbing surface. Therefore the chromatography of trace amounts is governed by adsorption-desorption reactions of single molecules with the column surface.

Up to now the behavior of trace amounts of $\mathrm{W}$ in the $\mathrm{O}_{2}-\mathrm{H}_{2} \mathrm{O}_{(\mathrm{g})} / \mathrm{SiO}_{2(\mathrm{~s})}$-system has been studied only incompletely. In dry oxygen carrier-free $\mathrm{W}$ could not be volatilized at a temperature of $1430 \mathrm{~K}$ [19]. In presence of moist oxygen $\mathrm{W}$ is much more volatile which has been explained by formation of $\mathrm{WO}_{2}(\mathrm{OH})_{2}[19$, 20]. Information about the basic reactions and thermodynamic state functions are not available.

As mentioned above, the formation of polymers can be ruled out owing to the low particle concentration. $\mathrm{WO}_{3}$ and $\mathrm{WO}_{2}(\mathrm{OH})_{2}$ should be the most stable species in the studied chemical system. $\mathrm{WO}_{2}(\mathrm{OH})_{2}$ is not known in the solid state. Nevertheless, an adsorption of this species has to be taken into account:

$$
\begin{array}{ll}
\mathrm{WO}_{3(\mathrm{~g})} & \rightleftarrows \mathrm{WO}_{3(\mathrm{ads})} \\
\mathrm{WO}_{2}(\mathrm{OH})_{2(\mathrm{~g})} & \rightleftarrows \mathrm{WO}_{2}(\mathrm{OH})_{2(\mathrm{ads})} \\
\mathrm{WO}_{2}(\mathrm{OH})_{2(\mathrm{~g})} & \rightleftarrows \mathrm{WO}_{3(\mathrm{ads})}+\mathrm{H}_{2} \mathrm{O}_{(\mathrm{g})} .
\end{array}
$$

An indirect evidence of the formed species is possible, if data predicted on the basis of thermodynamic arguments and model calculations correspond with data

\begin{tabular}{|c|c|c|c|}
\hline Species & $\begin{array}{c}\Delta H^{\circ} \\
{\left[\mathrm{kJ} \cdot \mathrm{mol}^{-1}\right]}\end{array}$ & $\begin{array}{c}S^{\circ} \\
{\left[\mathrm{J} \cdot \mathrm{mol}^{-1} \cdot \mathbf{K}^{-1}\right]}\end{array}$ & Literature \\
\hline $\begin{array}{l}\mathrm{H}_{2} \mathrm{O}_{(\mathrm{g})} \\
\mathrm{O}_{2(\mathrm{~g})}\end{array}$ & $\begin{array}{c}-241.83 \pm 0.04 \\
-241.86 \\
0\end{array}$ & $\begin{array}{l}188.73 \\
188.82 \\
205.15 \\
205.04 \\
205.15\end{array}$ & $\begin{array}{l}{[18]} \\
{[8]} \\
{[8]} \\
{[18]} \\
{[16]}\end{array}$ \\
\hline$W_{(s)}$ & 0 & $\begin{array}{c}32.6 \pm 0.4 \\
32.66 \\
32.68\end{array}$ & $\begin{array}{l}{[14]} \\
{[15]} \\
{[16]}\end{array}$ \\
\hline$W_{(B)}$ & $\begin{array}{c}849.9 \pm 12.6 \\
854.1\end{array}$ & $\begin{array}{l}173.96 \\
173.96\end{array}$ & $\begin{array}{l}{[14]} \\
{[15]}\end{array}$ \\
\hline $\begin{array}{l}W_{(s)} \\
W_{(g)}\end{array}$ & $\begin{array}{c}- \\
422.58 \\
(427.0) \\
425.38\end{array}$ & $\begin{array}{c}- \\
245.80 \\
(247.0) \\
245.77\end{array}$ & $\begin{array}{l}{[8]} \\
{[15]} \\
{[16]}\end{array}$ \\
\hline $\mathrm{WO}_{2(\mathrm{~g})}$ & $\begin{array}{c}-589.69 \\
-590.1 \pm 6.3 \\
-590.09 \\
-590.09 \\
76.57 \\
(62.8) \\
76.62\end{array}$ & $\begin{array}{c}50.53 \\
50.6 \pm 1.7 \\
50.58 \\
50.58 \\
285.50 \\
(284.7) \\
285.54\end{array}$ & $\begin{array}{l}{[8]} \\
{[14]} \\
{[15]} \\
{[16]} \\
{[8]} \\
{[15]} \\
{[16]}\end{array}$ \\
\hline $\mathrm{WO}_{3(\mathrm{~s})}$ & $\begin{array}{c}-842.91 \\
-843.4 \pm 2.9 \\
-843.43 \\
-843.47\end{array}$ & $\begin{array}{c}75.90 \\
75.95 \pm 1.256 \\
75.95 \\
75.95\end{array}$ & $\begin{array}{l}{[8]} \\
{[14]} \\
{[15]} \\
{[16]}\end{array}$ \\
\hline $\mathrm{WO}_{3(\mathrm{~g})}$ & $\begin{array}{c}-292.88 \\
(-293.1) \\
-293.08\end{array}$ & $\begin{array}{r}286.44 \\
(284.7) \\
286.38\end{array}$ & $\begin{array}{l}{[8]} \\
{[15]} \\
{[16]}\end{array}$ \\
\hline$\left(\mathrm{WO}_{3}\right)_{2(\mathrm{~g})}$ & $\begin{array}{l}-1163.99 \\
(-1159.7) \\
-1164.77\end{array}$ & $\begin{array}{c}415.60 \\
(414.5) \\
415.75\end{array}$ & $\begin{array}{l}{[8]} \\
{[15]} \\
{[16]}\end{array}$ \\
\hline$\left(\mathrm{WO}_{3}\right)_{3(\mathrm{~g})}$ & $\begin{array}{l}-2022.91 \\
-1958.0 \\
(-2026.4) \\
-2024.74\end{array}$ & $\begin{array}{r}504.67 \\
(506.6) \\
504.93\end{array}$ & $\begin{array}{l}{[8]} \\
{[17]} \\
{[15]} \\
{[16]}\end{array}$ \\
\hline$\left(\mathrm{WO}_{3}\right)_{4(\mathrm{~g})}$ & $\begin{array}{r}-2804.12 \\
(-2809.3) \\
2805.99\end{array}$ & $\begin{array}{r}605.27 \\
(607.1) \\
605.41\end{array}$ & $\begin{array}{l}{[8]} \\
{[15]} \\
{[16]}\end{array}$ \\
\hline $\mathrm{WO}_{2}(\mathrm{OH})_{2(\mathrm{~s})}$ & $\begin{array}{l}-1131.89 \\
-1130.44 \\
-1131.0 \\
-1132.53\end{array}$ & $\begin{array}{c}144.77 \\
(138.2) \\
144.77 \\
144.86\end{array}$ & $\begin{array}{l}{[8]} \\
{[15]} \\
{[17]} \\
{[16]}\end{array}$ \\
\hline $\mathrm{WO}_{2}(\mathrm{OH})_{2(\mathrm{~g})}$ & $\begin{array}{l}-905.84 \\
(-908.5) \\
-906.44\end{array}$ & $\begin{array}{c}352.00 \\
(351.7) \\
351.69\end{array}$ & $\begin{array}{l}{[8]} \\
{[15]} \\
{[16]}\end{array}$ \\
\hline
\end{tabular}

Table 1. Standard enthalpies and entropies of elements and compounds in the system tungsten-oxygen-water vapor $(T=298 \mathrm{~K})$ *

* Values in italics are used for calculations in the present work.

evaluated from experimental results. For simple reversible adsorption reactions the standard enthalpy of adsorption $\Delta H_{\text {ads }}^{\circ}$ on quartz-glass and the deposition temperature $T_{D}$ in a thermochromatographic column can be calculated from the standard enthalpy of sublimation $\Delta H_{298, \text { sub }}^{\circ}$ on the basis of semi-empirical relations between these quantities found for oxides (hydroxides) on quartz-glass surfaces [21]. The mobile adsorption model was used to estimate values of the standard entropy of adsorption $\Delta S_{\text {ads }}^{\circ}[22,23]$. 
Table 2. Calculated thermodynamic functions for relevant transport processes

\begin{tabular}{|c|c|c|c|}
\hline $\begin{array}{l}\text { Reaction } \\
\text { (adsorption) }\end{array}$ & $\begin{array}{c}\Delta H_{298}^{\circ} \\
\left(\mathrm{kJ} \cdot \mathrm{mol}^{-1}\right]\end{array}$ & $\begin{array}{c}\Delta S_{298}^{\circ} \\
{\left[\mathrm{J} \cdot \mathrm{mol}^{-1} \cdot \mathrm{K}^{-1}\right]}\end{array}$ & $\begin{array}{c}T_{D} \\
{[\mathbf{K}]}\end{array}$ \\
\hline simple reversible adsorption & $\Delta H_{\text {ads }}^{\circ}$ & $\Delta S_{\mathrm{ads}}^{\circ}$ & \\
\hline $\begin{array}{l}\mathrm{WO}_{2(\mathrm{~g})} \rightleftarrows \mathrm{WO}_{2(\mathrm{ads})} \\
\mathrm{WO}_{3 \mathrm{(g)}} \rightleftarrows \mathrm{WO}_{3 \mathrm{ads}} \\
\mathrm{WO}_{2}(\mathrm{OH})_{2(\mathrm{~g})} \rightleftarrows \mathrm{WO}_{2}(\mathrm{OH})_{2(\mathrm{ads})}\end{array}$ & $\begin{array}{l}-476.6 \pm 36.2 \\
-396.4 \pm 31.3 \\
-172.9 \pm 17.7\end{array}$ & $\begin{array}{l}-162.2 \pm 0.2 \\
-162.7 \pm 0.2 \\
-164.5 \pm 0.2\end{array}$ & $\begin{array}{c}1956 \pm 200 \\
1789 \pm 174 \\
765 \pm 99\end{array}$ \\
\hline dissociative adsorption & $\Delta H_{\mathrm{diss.ads}}^{\circ}$ & $\Delta S_{\text {diss.ads }}^{\circ}$ & \\
\hline $\mathrm{WO}_{2}(\mathrm{OH})_{2(\mathrm{~g})} \rightleftharpoons \mathrm{WO}_{3(\mathrm{ads})}+\mathrm{H}_{2} \mathrm{O}_{(\mathrm{g})}$ & $-25.3 \pm 31.3$ & $-39.5 \pm 0.2$ & \\
\hline
\end{tabular}

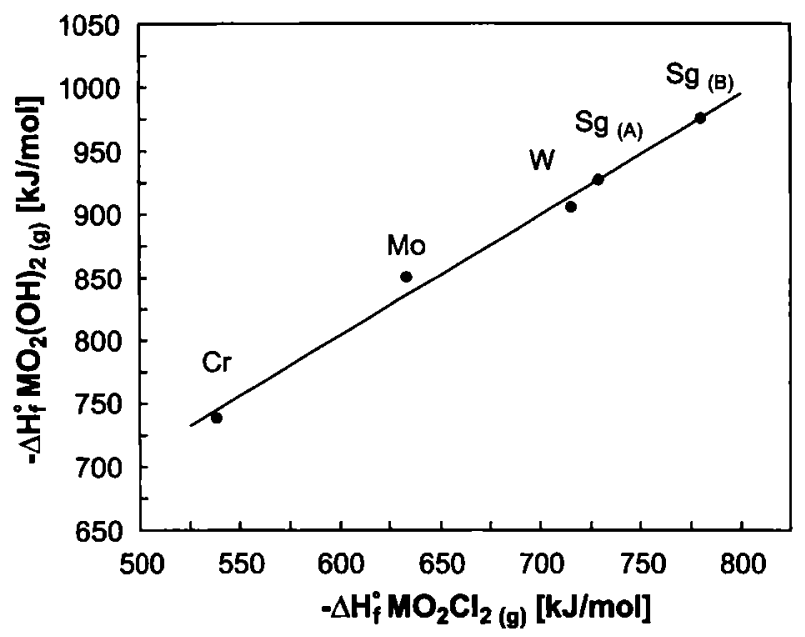

Fig. 1. Standard formation enthalpies of the oxychlorides $\mathrm{MO}_{2} \mathrm{Cl}_{2(\mathrm{~g})}$ and oxide hydroxides $\mathrm{MO}_{2}(\mathrm{OH})_{2(\mathrm{~g})}$ for all group $6 \mathrm{el}-$ ements. $\mathrm{Sg}_{(\mathrm{A})}$ was calculated with $\Delta H^{\circ} \mathrm{Sg}_{(\mathrm{g})}=897 \mathrm{~kJ} / \mathrm{mol}$ [26], $\mathrm{Sg}_{(\mathrm{B})}$ with $\Delta H^{\circ} \mathrm{Sg}_{(\mathrm{g})}=1030 \mathrm{~kJ} / \mathrm{mol}[27]$.

Thermodynamic state functions for the more complex reaction (3) were calculated in the following way:

$$
\begin{aligned}
\Delta H_{\text {diss.ads }}^{\circ} & =\Delta H_{\mathrm{f}}^{\circ} \mathrm{WO}_{3(\mathrm{~g})}+\Delta H_{\mathrm{f}}^{\circ} \mathrm{H}_{2} \mathrm{O}_{(\mathrm{g})} \\
& -\Delta H_{\mathrm{f}}^{\circ} \mathrm{WO}_{2}(\mathrm{OH})_{2(\mathrm{~g})}+\Delta H_{\mathrm{ads}}^{\circ} \mathrm{WO}_{3} \\
\Delta S_{\text {diss.ads }}^{\circ} & =S^{\circ} \mathrm{WO}_{3(\mathrm{~g})}+S^{\circ} \mathrm{H}_{2} \mathrm{O}_{(\mathrm{g})} \\
& -S^{\circ} \mathrm{WO}_{2}(\mathrm{OH})_{2(\mathrm{~g})}+\Delta S_{\text {ads }}^{\circ} \mathrm{WO}_{3} .
\end{aligned}
$$

Table 2 gives the standard enthalpies, entropies and deposition temperatures for the reactions (1)-(3) calculated from the thermodynamic data listed in Table 1. The given error limits result from the errors of the correlations and of the literature data. However, the error limits of literature data are often not available. The real errors may therefore be much greater than those given in Table 2.

Standard formation enthalpies of the oxychlorides $\mathrm{MO}_{2} \mathrm{Cl}_{2(\mathrm{~g})}[8,24-27]$ and oxide hydroxides $\mathrm{MO}_{2}(\mathrm{OH})_{2(\mathrm{~g})}[8,18,26-28]$ for all group 6 elements are compared in Fig. 1. The values for $\mathrm{Sg}$ were calculated with $\Delta H^{\circ} \mathrm{Sg}_{(\mathrm{g})}=897 \mathrm{~kJ} / \mathrm{mol}$ [26] $\left(\mathrm{Sg}_{(\mathrm{A})}\right)$ and $\Delta H^{\circ} \mathrm{Sg}_{(\mathrm{g})}=1030 \mathrm{~kJ} / \mathrm{mol}[27]\left(\mathrm{Sg}_{(\mathrm{B})}\right)$, respectively. As can be deduced, within this group the compounds become more stable with increasing atomic number from $\mathrm{Cr}$ to $\mathrm{W}$. The trend is expected to be continued for Sg. First Sg experiments confirm the formation of a stable oxychloride [1]. The oxide hydroxides are generally more stable than the corresponding oxychlorides.

\subsection{Evaluation of the experiments}

The starting point of the evaluation of thermochromatography experiments with trace amounts is the transport equation derived under simplified assumptions [29].

$$
\frac{d z}{d t}=\frac{u}{1+k_{i}}
$$

where $z$ is the length coordinate in the column, and $t$ is the time. The velocity $u$ and the corrected partition coefficient $k_{i}$ are temperature-dependent functions.

\section{Eichler-Zvara approach}

In the Eichler-Zvara approach the main approximation for a solution of Eq. (6) was the assumption of a linear temperature profile $T=T_{S}-g \cdot z$ with $g=$ const. $>0$. An approximative solution of Eq. (6) was possible in order to get the enthalpy using a modified exponential integral function of $x, E i^{*}(x)$, with the asymptotics $\exp (x) / x$.

The following equations derived by Eichler $e t$ al. $[23,30,31]$ can be used to evaluate the adsorption enthalpies from the parameters of thermochromatographic experiments:

$$
\begin{aligned}
f\left(E i^{*}\right)= & \frac{t_{r} \cdot v_{0} \cdot g}{a \cdot T_{0} \cdot(1 \mathrm{~cm}) \cdot e^{\frac{\Delta S_{\text {ddc }}^{\circ}}{R}}} \text { for }(1,2) \\
f\left(E i^{*}\right)= & \frac{t_{r} \cdot v_{0} \cdot g \cdot c_{\mathrm{gas}}\left(\mathrm{H}_{2} \mathrm{O}\right)}{a \cdot T_{0} \cdot c_{\mathrm{ads}}^{\circ}\left(\mathrm{WO}_{3}\right) \cdot e^{\frac{\Delta S_{\mathrm{dis} . \mathrm{ads}}^{\circ}}{R}} \text { for (3) }}
\end{aligned}
$$

with

$$
\begin{aligned}
f\left(E i^{*}\right) & =E i^{*}\left(\frac{-\Delta H_{\text {ads/diss.ads }}^{\circ}}{R T_{D}}\right) \\
& -E i^{*}\left(\frac{-\Delta H_{\text {ads/diss.ads }}^{\circ}}{R T_{S}}\right)
\end{aligned}
$$

where $t_{r}$ is the retention time (= exposure time), $v_{0}$ is the gas flow rate under standard conditions, $g$ is 
the temperature gradient, $a$ is the surface area per unit of column length, $T_{0}$ is the standard temperature, $c_{\text {gas }}\left(\mathrm{H}_{2} \mathrm{O}\right)$ is the concentration of $\mathrm{H}_{2} \mathrm{O}$ in the gaseous phase, $c_{\text {ads }}^{\circ}\left(\mathrm{WO}_{3}\right)$ is the standard concentration of $\mathrm{WO}_{3}$ in the adsorbed state according to [23, 31], $\Delta S_{\text {adsdiss.ads }}^{\circ}$ is the standard entropy of adsorption/dissociative adsorption, $T_{D}$ is the deposition temperature, $T_{S}$ is the starting temperature, and $\Delta H_{\text {adsdiss.ads }}^{\circ}$ is the standard enthalpy of adsorption/dissociative adsorption.

The Eichler-Zvara approach was used to visualize experimental data and to compare these data with model calculations (Fig. 6).

\section{TECPROF}

The Eichler-Zvara approach is a very convenient tool to determine standard enthalpies. However, the temperature profile is assumed to be linear, which is often not realizable. The more the temperature gradient deviates from a constant value the greater is the error of the calculated enthalpy value.

An exact solution of Eq. (6) needs the temperature profile of the tube $T=f(z)$. The inverse function $z=$ $f^{-1}(T)$ or shorter $z=z(T)$ exists, if the temperature function is monotonous in the relevant region.

Eq. (6) can be rewritten without any approximations to:

$$
0=t_{r}+\int_{T_{D}}^{T_{s}} \frac{1+k_{i}}{\mathrm{u}} \frac{\mathrm{d} z(T)}{\mathrm{d} T} \mathrm{~d} T .
$$

From Eq. (9) results that for each enthalpy the deposition temperature depends on the "temperature history" during the transport through the tube. The calculation was performed with the FORTRAN program TECPROF $[32,33,38]$. The function $\mathrm{d} z(T) / \mathrm{d} T$ was assigned with high accuracy from the measured profile by means of a spline procedure.

The computer code TECPROF allows the fast calculation of exact enthalpy values considering real temperature profiles.

Fig. 2 shows the influence of the temperature profile of the tube on the deposition temperature of a given species in dependence on the enthalpy of the adsorption reaction.

From Fig. 2 one can also deduce the difference between the exact enthalpy value and the enthalpy determined assuming a linear temperature profile. The deviations depend on the real temperature profile. For the given data the mean error is in the range of 5$10 \%$.

All thermochromatography experiments carried out in this work were evaluated by means of the computer code TECPROF.

\section{Monte Carlo simulation}

Monte Carlo simulation of chromatography by means of the models described in detail in $[34,35]$ is a further method to evaluate experimental data. These models

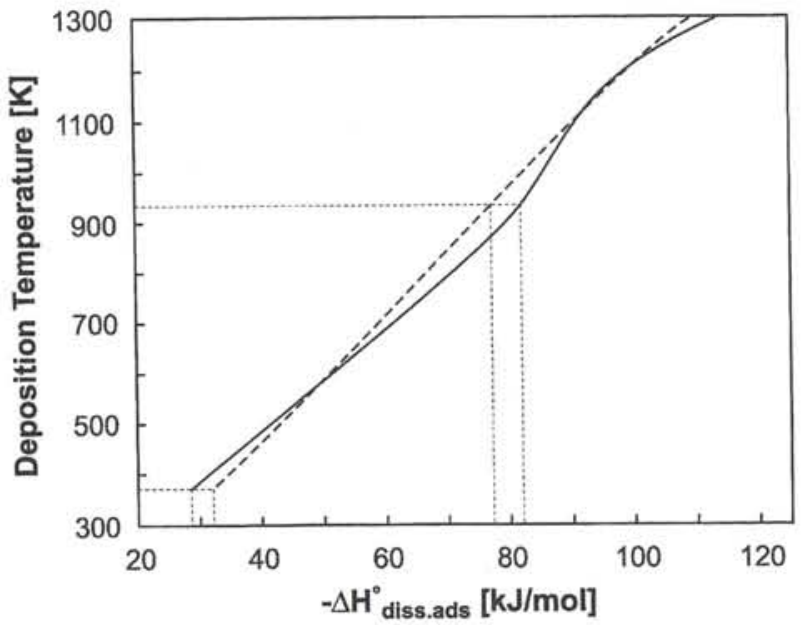

Fig. 2. Dependence of the deposition temperature on $\Delta H_{\text {diss.ads }}^{\circ}$ for $\mathrm{WO}_{2}(\mathrm{OH})_{2(\mathrm{~g})} \rightleftarrows \mathrm{WO}_{3(\text { ads })}+\mathrm{H}_{2} \mathrm{O}_{(\mathrm{g})}$; solid: real temperature profile, see Fig. 3, dashed: ideal linear temperature profile. $T_{s}=1450 \mathrm{~K}, t_{\exp }=30 \mathrm{~min}, v_{0}=750 \mathrm{ml} / \mathrm{min}, p\left(\mathrm{H}_{2} \mathrm{O}\right)=$ $780 \mathrm{~Pa}, d_{i}=3.5 \mathrm{~mm}$. Points of corresponding mean temperature gradients are marked by auxiliary lines: Note that the resulting enthalpies differ from each other in dependence on the deviation of the real from the linear profile.

allow to simulate gas chromatography experiments and to calculate either zone profiles in thermochromatography or expected yields of a chemical species for a given adsorption enthalpy and temperature in isothermal chromatography. Experimental conditions such as temperature profiles, different carrier gas flow rates, injection profiles, and the radioactive decay of species can easily be considered.

\section{Experimental}

\section{Production of the radionuclides}

The $\mathrm{W}$ isotopes ${ }^{175} \mathrm{~W}\left(t_{1 / 2}=34 \mathrm{~min}\right),{ }^{176} \mathrm{~W}\left(t_{1 / 2}=\right.$ $2.5 \mathrm{~h}),{ }^{177} \mathrm{~W}\left(t_{1 / 2}=2.25 \mathrm{~h}\right)$ were produced by bombarding a stack of $15 \mathrm{Hf}$ foils $(15 \mu \mathrm{m})$ with $49 \mathrm{MeV}$ $\alpha$-particles at the PSI PHILIPS cyclotron.

The short-lived $\mathrm{W}$ isotopes ${ }^{166} \mathrm{~W}\left(t_{1 / 2}=18.8 \mathrm{~s}\right)$, ${ }^{168} \mathrm{~W}\left(t_{1 / 2}=51 \mathrm{~s}\right),{ }^{169} \mathrm{~W}\left(t_{1 / 2}=76 \mathrm{~s}\right)$ were formed in the ${ }^{152} \mathrm{Gd}\left({ }^{20} \mathrm{Ne}\right.$, xn) reaction at a beam energy of $120 \mathrm{MeV}$. The target, containing $0.5 \mathrm{mg} / \mathrm{cm}^{2}$ of ${ }^{152} \mathrm{Gd}$ (enriched: $26 \%$ ) was prepared by electrodeposition on a $15 \mu \mathrm{m}$ Be foil.

${ }^{99} \mathrm{Mo}\left(t_{1 / 2}=65.94 \mathrm{~h}\right)$ was produced by fission of ${ }^{235} \mathrm{U}$ with thermal neutrons at the PSI SAPHIR reactor. It was used as a tracer to study the influence of $\mu \mathrm{g}$ amounts of $\mathrm{MoO}_{3}$ on the transport and deposition behavior of trace amounts of $\mathrm{W}$.

A $\mathrm{He} / \mathrm{C}$ - and a $\mathrm{He} / \mathrm{MoO}_{3}$-jet were used to transport the reaction products through a capillary from the target chamber to the experimental setup. The gas-jet was operated with a He-flow rate of $1.0 \mathrm{l} / \mathrm{min}$. Carbon aerosol particles were obtained by means of a spark discharge generator. $\mathrm{MoO}_{3}$ aerosol particles were gen- 


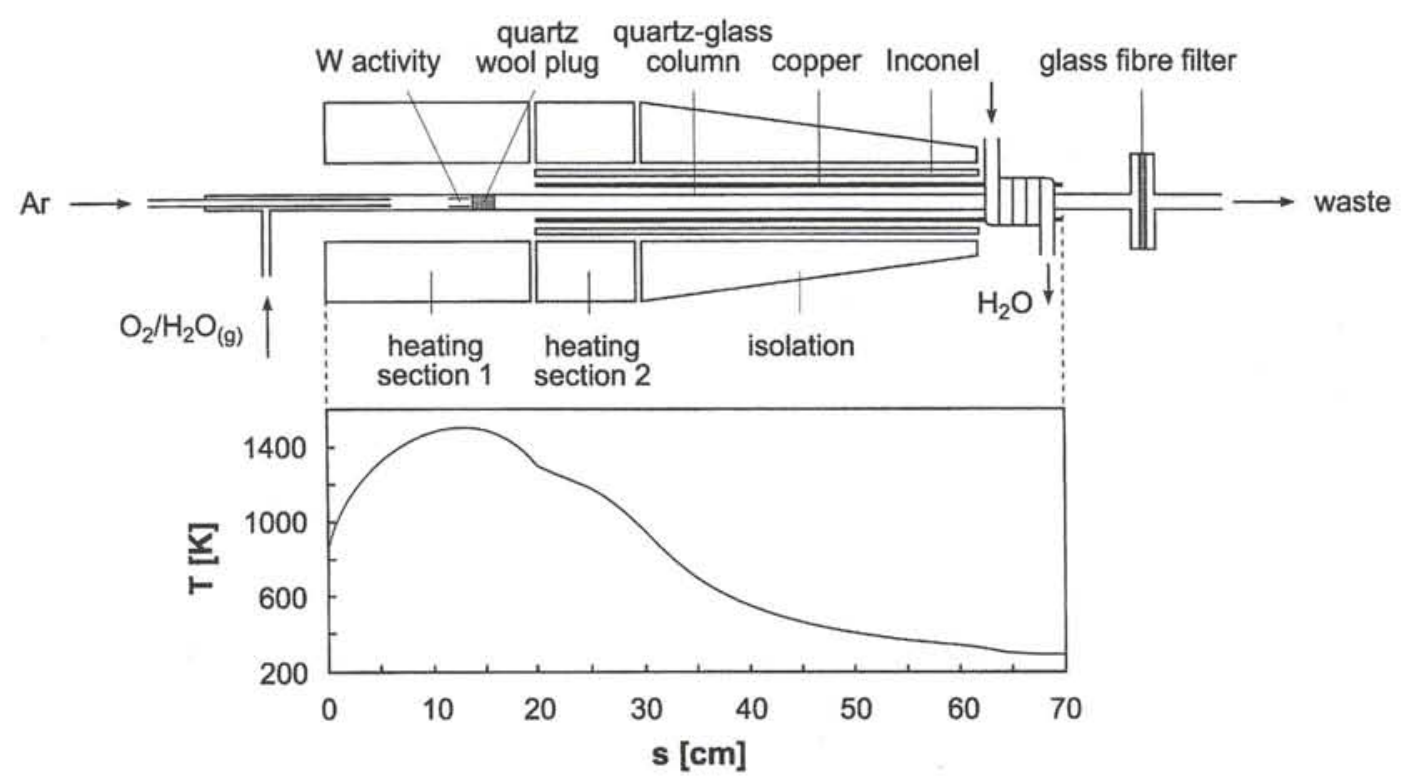

Fig. 3. Experimental arrangement for thermochromatography experiments and temperature distribution along the thermochromatographic column. The furnace was operated vertically, the gas passes from bottom to the top.

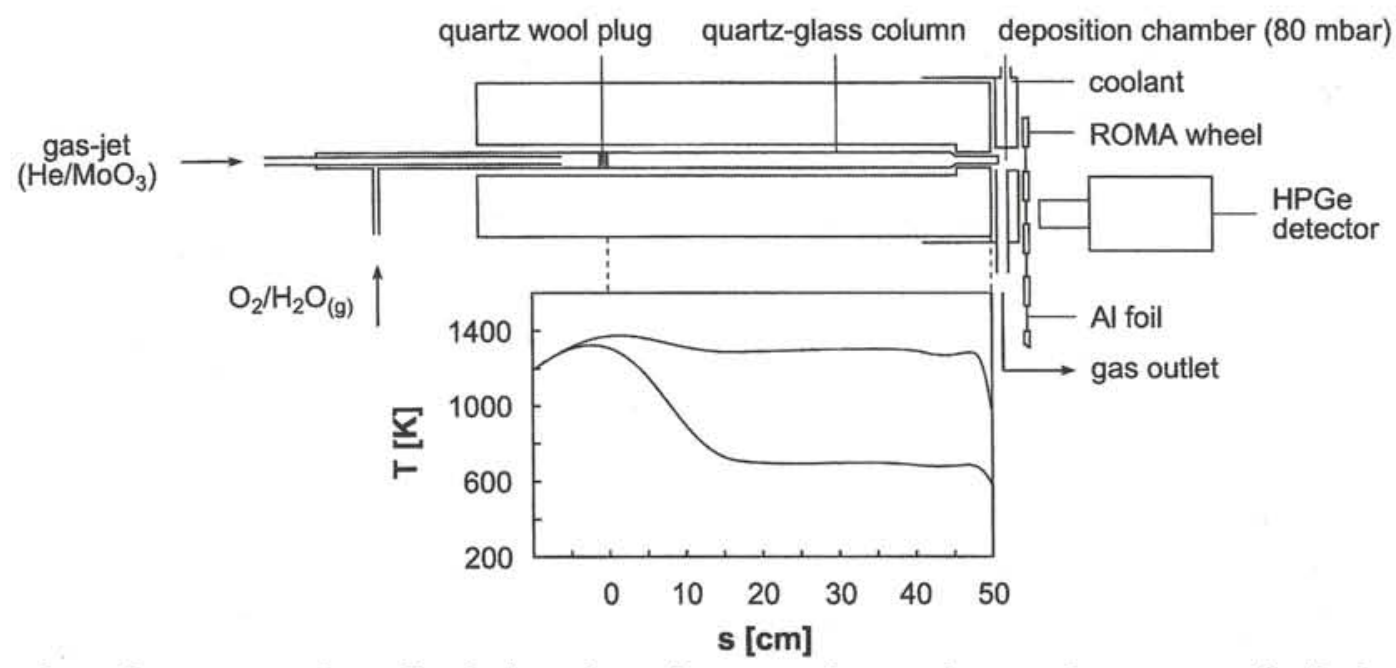

Fig. 4. Experimental arrangement for on-line isothermal gas chromatography experiments and temperature distribution along the isothermal column.

erated by sublimation of $\mathrm{MoO}_{3}$ at $900 \mathrm{~K}$ into flowing He.

\section{Thermochromatography}

Basically, the experimental setup corresponds to the arrangement described in detail in [2]. Fig. 3 shows the experimental arrangement for the thermochromatographic studies and the temperature distribution along the chromatographic column. The $70 \mathrm{~cm}$ long oven consists of a $15 \mathrm{~cm}$ long preheating section, which was operated at a temperature of $1450 \mathrm{~K}$ and a $55 \mathrm{~cm}$ long chromatographic section. A medium temperature gradient of $25 \mathrm{~K} / \mathrm{cm}$ was adjusted by means of the two heating sections and the water coolant at the end of the furnace.
Empty quartz-glass tubes with a length of $85 \mathrm{~cm}$ and an inner diameter of $3.5 \mathrm{~mm}$ were used as chromatography columns. The substance to be studied was placed into the starting position where the highest temperature could be established and was separated from the chromatographic zone by a $20 \mathrm{~mm}$ long quartz wool plug. A mixture of $500 \mathrm{ml} / \mathrm{min} \mathrm{Ar}$ and $250 \mathrm{ml} /$ $\min \mathrm{O}_{2}$ was used as the carrier gas. The oxygen or the total gas was moistened by bubbling through water. In dry oxygen the remaining water vapor pressure was $\ll$ $3 \mathrm{~Pa}$, but could not be measured exactly. Thermochromatography was started by opening the gas supply.

Species leaving the column were collected on a glass fibre filter. The exposure time in all experiments was $30 \mathrm{~min}$. To finish an experiment and to fix the 
"inner thermochromatogram" the quartz-glass column was removed from the oven and cooled down by rinsing with cold water. Then the nuclide distribution along the column was measured by $\gamma$-ray spectroscopy of $2 \mathrm{~cm}$ column sections with a Ge(Li) or a HPGe detector.

For experiments with carrier-free $\mathrm{W}$ isotopes the nuclides attached to graphite aerosol particles were collected on a small paper filter for $1-2 \mathrm{~h}$. Then the filter was inserted in the starting position of a quartzglass column, fixed with quartz wool and burned in a dry oxygen stream $(50 \mathrm{ml} / \mathrm{min})$ at a temperature of $<900 \mathrm{~K}$. In test experiments it was proven that $<10 \%$ of the $\mathrm{W}$ activity were lost without any contaminations of the chromatographic column.

Experiments with a homologous carrier were prepared by collecting $\mathrm{MoO}_{3}$ aerosol particles loaded with fission product nuclides on a paper filter for at least $12 \mathrm{~h}$. The filter was burned as described above together with a filter loaded with $\mathrm{W}$ nuclides attached to graphite aerosol particles. The Mo amount was determined by neutron activation analysis comparing the ${ }^{99} \mathrm{Mo}$ activity of samples and standards $(10 \mu \mathrm{g}$ and $100 \mu \mathrm{g}$ Mo as $\mathrm{MoO}_{3}$ ).

\section{Is othermal on-line gas chromatography}

The experimental setup is shown in Fig. 4. The chromatography furnace consists of five heating sections which can be operated independently. Differently shaped chromatography columns with outer diameters up to $18 \mathrm{~mm}$ can be used at isothermal temperatures up to $1375 \mathrm{~K}$.

The columns used in this study were straight open tubular quartz-glass columns with the following specifications: (a) $3.5 \mathrm{~mm}$ inner diameter, (b) $6 \mathrm{~cm}$ long preheating section, (c) constriction for positioning quartz wool as a high temperature reaction zone, (d) $38 \mathrm{~cm}$ long isothermal zone, (e) capillary outlet. The temperature of the reaction zone was $1350 \mathrm{~K}$, the isothermal column temperature was varied between 800 and $1350 \mathrm{~K}$, whereas the temperature at the outlet was hold above $950 \mathrm{~K}$. The nuclides attached to $\mathrm{MoO}_{3}$ aerosol particles and transported by the $\mathrm{He}$ gas flow were continuously injected into the chromatography column. The gas-jet was operated with a He-flow rate of $1.0 \mathrm{~V} / \mathrm{min}$. At the column entrance, $0.5 \mathrm{l} / \mathrm{min} \mathrm{O}_{2}$, moistened with $\mathrm{H}_{2} \mathrm{O}$ at $323 \mathrm{~K}$ were added to form volatile oxide hydroxides. The partial pressure of water was measured to be $2.5 \mathrm{kPa}$ in the gas mixture.

To replace the time consuming reclustering step between chromatography and detection $[39,40]$, the volatile $\mathrm{W}$ species leaving the chromatography column were directly deposited on $\mathrm{Al}$ foils mounted on the circumference of the rotating wheel of the GSI ROtating wheel Multidetector Analyzer ROMA which was operated with a cycle time for collection and detection of $20 \mathrm{~s}$. To establish an optimum pressure for the direct deposition of about $\mathbf{8 0}$ mbar and at the same time a pressure below $5 \mathrm{mbar}$ in the detection positions of the ROMA chamber a separate deposition chamber was placed between column and rotating wheel. Furthermore, the deposition chamber was connected to a cooling thermostat and cooled the wheel. At a coolant temperature of $283 \mathrm{~K}$ the temperature of the rotating wheel at the first detection position did not exceed $298 \mathrm{~K}$. The activity of the foils was measured either by $\gamma$ - or $\alpha$-spectrometry. To measure the activity of the gas-jet the aerosol particles passing through an open unheated column were collected on glass fibre filters.

\section{Results and discussion}

\subsection{Off-line thermochromatography}

$\mathrm{W}$ was not volatilized in case of using dry oxygen as reactive admixture to the carrier gas. This result corresponds to the observations of Bayar et al. [19]. On account of the similarity of Mo and $\mathrm{W}$ it is to assume that $\mathrm{WO}_{3}$ has been formed. Unfortunately, the predicted deposition temperature (Table 2) for $\mathrm{WO}_{3}$ is higher than the maximum furnace temperature. It can be proven only by experiments at higher temperatures that $\mathrm{W}$ is transported via reaction (1). However, at $T>1450 \mathrm{~K}$ quartz cannot be used as column material.

With moist oxygen as a reactive gas admixture, $\mathrm{W}$ was volatilized. Typical thermochromatograms measured at different water vapor pressures are shown in Fig. 5. That is interpreted with the formation of $\mathrm{WO}_{2}(\mathrm{OH})_{2}$. The position of the observed deposition zone depends significantly on the vapor pressure of water indicating a dissociative adsorption of $\mathrm{WO}_{2}(\mathrm{OH})_{2}$ according to reaction (3)

$$
\mathrm{WO}_{2}(\mathrm{OH})_{2(\mathrm{~g})} \rightleftarrows \mathrm{WO}_{3(\mathrm{ads})}+\mathrm{H}_{2} \mathrm{O}_{(\mathrm{g})} \text {. }
$$

The variation of the water vapor pressure in the gas mixture in a wide range from $40 \mathrm{~Pa}$ to $2.3 \mathrm{kPa}$ corresponds to a shift of the deposition temperature of nearly $200 \mathrm{~K}$ and a shift of the peak position, but only of $4 \mathrm{~cm}$. The resulting enthalpy for reaction (3) was evaluated to be $\Delta H_{\text {diss.ads }}^{\circ}=-62 \pm 13 \mathrm{~kJ} / \mathrm{mol}$. The uncertainty results from the standard deviation $(1 \sigma)$ and the experimental error which is relatively large on account of the relation between deposition temperature and enthalpy. Uncertainties of the literature data used for the calculation of $\Delta S_{\text {diss.ads }}^{\circ}$ are not available. That means, that the uncertainty may be even higher than the given $13 \mathrm{~kJ} / \mathrm{mol}$.

As can be also seen in Fig. 5 the W nuclides were partly transported out of the furnace where they were collected on a glass fibre filter. This effect was observed in all experiments and is a result of the reaction of the column surface with water at high temperatures:

$$
\mathrm{SiO}_{2(\mathrm{~s})}+\mathrm{n} \mathrm{H}_{2} \mathrm{O}_{(\mathrm{g})} \rightleftarrows \mathrm{SiO}_{2} \cdot \mathrm{n} \mathrm{H}_{2} \mathrm{O}_{(\mathrm{g})} \text {. }
$$

At lower temperatures the silicic acid is deposited on the column surface according to reaction (10) or formes aerosol particles. W nuclides, which are not yet deposited at this temperatures may be attached to the 


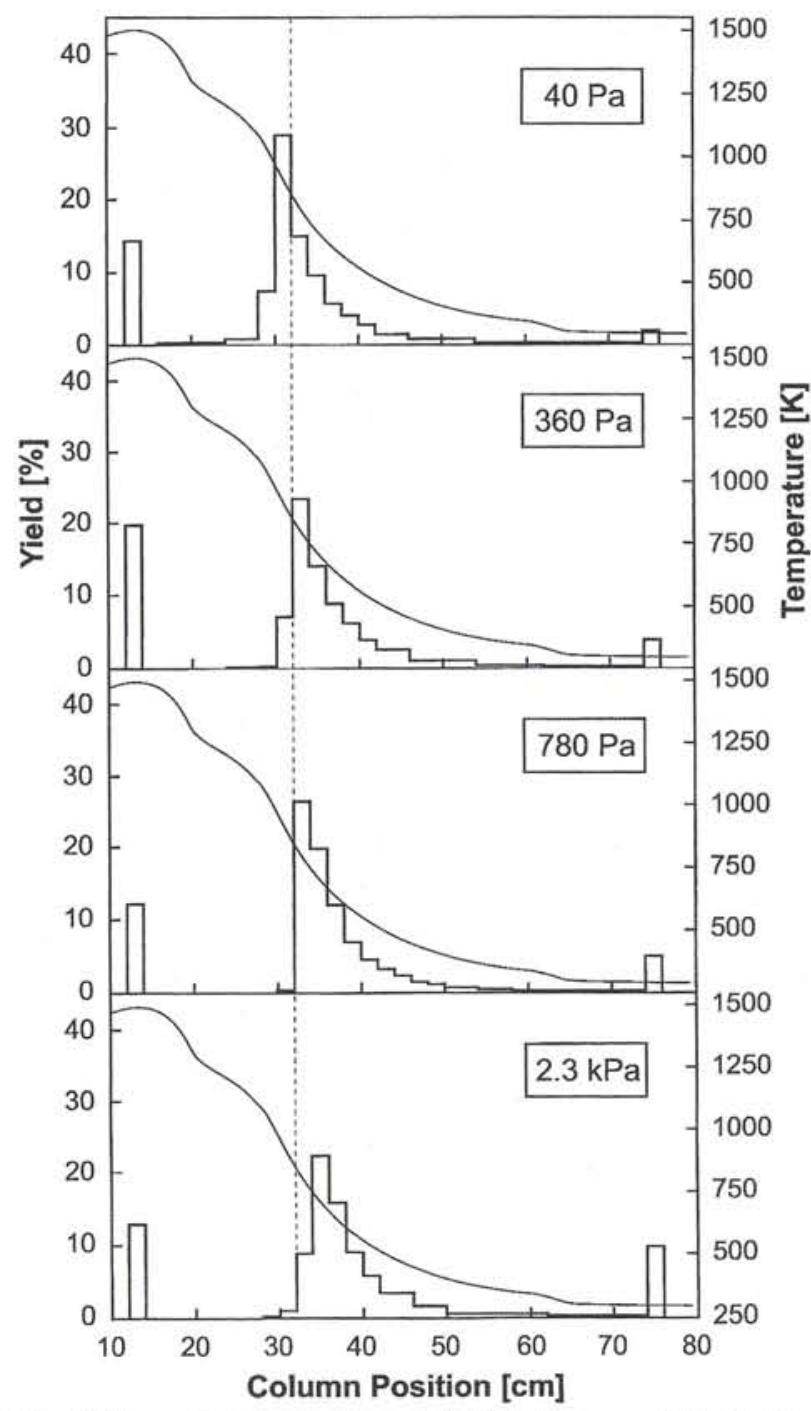

Fig. 5. Thermochromatograms of ${ }^{177} \mathrm{~W}$ in trace amounts at different water vapor pressures. $t_{\text {exp }}=30 \mathrm{~min}, v_{0}(\mathrm{Ar})=500 \mathrm{ml} /$ $\min , v_{0}\left(\mathrm{O}_{2}\right)=250 \mathrm{ml} / \mathrm{min}$. The dashed line is an auxiliary line to guide the eye.

aerosol particles and transported out of the chromatographic section. The transported amount of $\mathrm{SiO}_{2}$ and so the number of aerosol particles grows with increasing humidity of the carrier gas. That's why the part of the $\mathrm{W}$ activity leaving the column increases with higher water vapor pressures.

In Fig. 6 experimental data are compared to model calculations. Assuming reactions (1) and (2), the experimental data are plotted according to Eq. (7) and are compared to $E i$-functions calculated with data from Table 2. Unfortunately, as mentioned above uncertainties of the literature data used for the determination of $\Delta H_{\text {ads, }}^{\circ} \Delta H_{\text {diss.ads }}^{\circ}$ and $\Delta S_{\text {diss.ads }}^{\circ}$ are not available. The uncertainties of the $E i *$-functions for reactions (1) and (2) result from the correlation between the enthalpies of sublimation and adsorption and should be regarded as a lower error limit. Nevertheless, it seems to be evident, that a simple adsorption of $\mathrm{WO}_{2}(\mathrm{OH})_{2}$ or even $\mathrm{WO}_{3}$ can be excluded. The

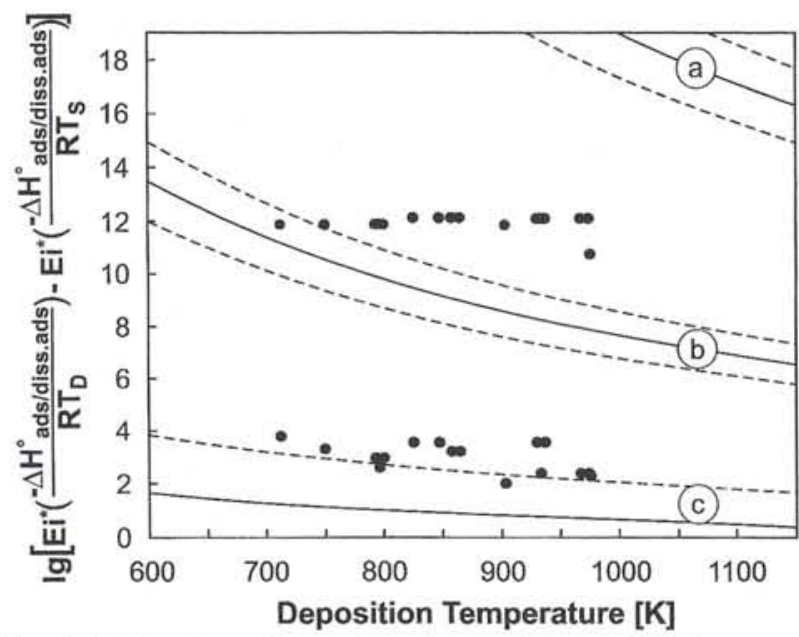

Fig. 6. Evaluation of the adsorption enthalpy of $W$ in trace amounts on a quartz surface in moist oxygen from the experimental deposition temperatures $T_{D}$. (a) The solid line is calculated for $\mathrm{WO}_{3(\mathrm{~g})} \rightleftarrows \mathrm{WO}_{3(\mathrm{ads})}$ with Eq. (7) using $\Delta H_{\mathrm{ads}}^{\circ}=-396$ $\mathrm{kJ} / \mathrm{mol}$, dashed lines give the uncertainty of $\pm 31 \mathrm{~kJ} / \mathrm{mol}$. (b) The solid line is calculated for $\mathrm{WO}_{2}(\mathrm{OH})_{2(\mathrm{~g})} \rightleftarrows \mathrm{WO}_{2}(\mathrm{OH})_{2 \text { (ads) }}$ with Eq. (7) using $\Delta H_{\text {ads }}^{\circ}=-173 \mathrm{~kJ} / \mathrm{mol}$, dashed lines give the uncertainty of $\pm 18 \mathrm{~kJ} / \mathrm{mol}$. (c) The solid line is calculated for $\mathrm{WO}_{2}(\mathrm{OH})_{2(\mathrm{~g})} \rightleftharpoons \mathrm{WO}_{3 \text { (ads) }}+\mathrm{H}_{2} \mathrm{O}_{(\mathrm{g})}$ with Eq. (8) using $\Delta H_{\text {diss.ads }}^{\circ}=-25 \mathrm{~kJ} / \mathrm{mol}$, dashed line gives the one-sided uncertainty of $-31 \mathrm{~kJ} / \mathrm{mol}$.

experimental data better compare with the $f\left(E i^{*}\right)$ values calculated for a dissociative adsorption of $\mathrm{WO}_{2}(\mathrm{OH})_{2}$ according to Eq. (8).

\subsection{Influence of a homologous carrier}

With respect to the physico-chemical characterization of $\mathrm{Sg}$ we studied the influence of macroscopic amounts of Mo as a homologous carrier in form of $\mathrm{MoO}_{3}$ on the transport and deposition behavior of $\mathrm{W}$. A modification of the column surface or formation of heteropolynuclear compounds can result in a completely changed transport behavior. In case of formation of heteropolynuclear compounds Mo and W should be deposited at the same position in the chromatographic column and would allow to demonstrate the chemical similarity of Mo and W by combined volatilization.

$\mathrm{MoO}_{3}$ is also often used as aerosol material to transport nuclides from a target chamber to an experimental arrangement. That is why we have to proof whether the chromatographic transport of $\mathrm{W}$ is influenced by $\mu$ g-amounts of this aerosol material.

Fig. 7 shows thermochromatograms obtained at different water vapor pressures and carrier amounts of 36-56 $\mu \mathrm{g} \mathrm{MoO}_{3}$. Deposition zones observed with carrier-free $\mathrm{W}$ are also shown for a better comparison:

- Mo and W are deposited at different temperatures.

- W is deposited at higher temperatures in comparison to experiments without adding a homologous carrier. 


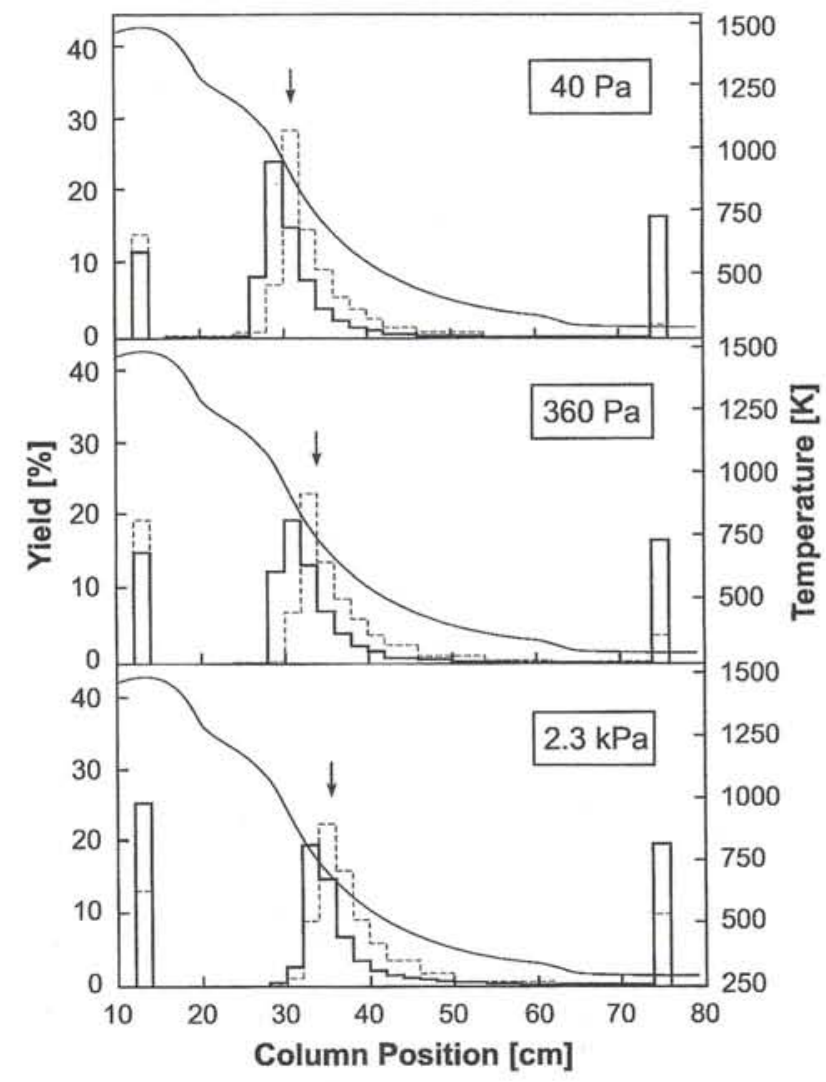

Fig. 7. Thermochromatograms of ${ }^{177} \mathrm{~W}$ in trace amounts by adding a homologous carrier $\left(\mathrm{MoO}_{3}\right)$ at different water vapor pressures; solid: with homologuous carrier, dashed: carrierfree W. The arrows mark the maximum of the Mo deposition. $v_{0}(\mathrm{Ar})=500 \mathrm{ml} / \mathrm{min}, v_{0}\left(\mathrm{O}_{2}\right)=250 \mathrm{ml} / \mathrm{min}$.

From the first observation one can conclude that amounts $\leq 56 \mu \mathrm{g} \mathrm{MoO}_{3}$ do not influence the transport of $\mathrm{W}$ by formation of heteropolynuclear complexes.

The covering of the quartz surface with $\mathrm{MoO}_{3}$ molecules could be a reason for the higher deposition temperatures if the interaction between $\mathrm{WO}_{3}$ and $\mathrm{MoO}_{3}$ is stronger than that between $\mathrm{WO}_{3}$ and the quartz-glass surface.

\subsection{On-line isothermal gas chromatography}

$\mathrm{Sg}$ experiments were modelled by isothermal on-line gas chromatography experiments with short-lived $\mathrm{W}$ isotopes. Furthermore, these experiments had the aim to verify the results of the thermochromatography experiments.

Maximum yields of $53 \%$ for ${ }^{166} \mathrm{~W}\left(t_{1 / 2}=18.8 \mathrm{~s}\right)$ and $63 \%$ for ${ }^{168} \mathrm{~W}\left(t_{1 / 2}=51 \mathrm{~s}\right)$ were measured at $1350 \mathrm{~K}$ relative to the activity of the gas-jet.

Fig. 8 shows relative yields (maximum value $=$ $100 \%$ ) of ${ }^{166} \mathrm{~W}$ and ${ }^{168} \mathrm{~W}$ as a function of the isothermal temperature together with yield curves calculated by Monte Carlo simulation for chromatography corresponding to reaction (3). The best fit of the experimental data was obtained with enthalpy values of $\Delta H_{\text {diss.ads }}^{\circ}=-54$ and $-56 \mathrm{~kJ} / \mathrm{mol}$, respectively. These

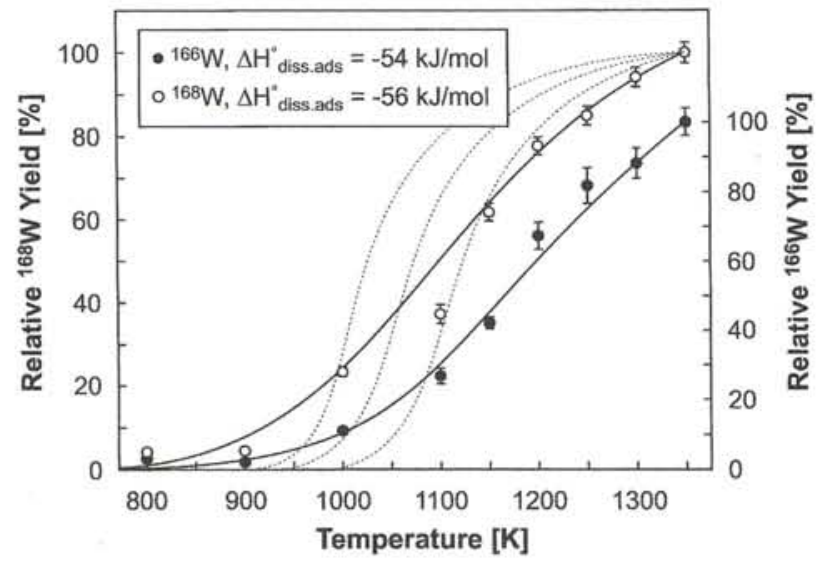

Fig. 8. Relative yields (maximum value $=100 \%$ ) of ${ }^{166} \mathrm{~W}$ and ${ }^{168} \mathrm{~W}$ as a function of the isothermal temperature together with yield curves calculated by Monte Carlo simulation. The dashed lines were obtained assuming a simple reversible adsorption reaction of $\mathrm{WO}_{2}(\mathrm{OH})_{2}$ with $\Delta H_{\mathrm{ads}}^{\circ}=-210 \mathrm{~kJ} / \mathrm{mol}$ to $-230 \mathrm{~kJ} /$ $\mathrm{mol}$ in steps of $10 \mathrm{~kJ} / \mathrm{mol}$.

values correspond quite well with the value of $\Delta H_{\text {diss.ads }}^{\circ}=-62 \pm 13 \mathrm{~kJ} / \mathrm{mol}$ derived from thermochromatography experiments. The retention time spent by the $\mathrm{W}$ species during their travel from the column entrance to the $\mathrm{Al}$ foil was determined to be about $20 \mathrm{~s}$. From the nuclide yield ratio at $1350 \mathrm{~K}$ a retention time of $8 \mathrm{~s}$ was calculated [36] which seems to be a more reliable value since a few unproven assumptions were used to simulate the chromatographic process.

The dashed lines also shown in Fig. 8 were obtained for ${ }^{168} \mathrm{~W}$ assuming simple reversible adsorption of $\mathrm{WO}_{2}(\mathrm{OH})_{2}$ as the basic process of chromatography (reaction (2)) with hypothetical enthalpy values of $\Delta H_{\text {ads }}^{\circ}$ between $-210 \mathrm{~kJ} / \mathrm{mol}$ and $-230 \mathrm{~kJ} / \mathrm{mol}$. As easily can be seen, none of these curves can reproduce the experimental data. This is taken as a further evidence that the gas chromatography of $\mathrm{WO}_{2}(\mathrm{OH})_{2}$ in quartz-glass columns is not governed by reaction (2), but by reaction (3) and has to be considered as reaction gas chromatography [35].

The alpha spectrometric measurements were carried out in $2 \pi$ geometry with a resolution of $30 \mathrm{keV}$ (FWHM). Nuclides like ${ }^{152} \mathrm{Ho}$ and ${ }^{151} \mathrm{Dy}$, produced in transfer reactions of the target nuclide were retained nearly quantitatively in the column. Decontamination factors between $10^{2}$ and $10^{3}$ were achieved.

The results are very promising with regard to future studies of Sg. However, as a prerequisite for the unequivocal detection of $\mathrm{Sg}$ alpha spectroscopy in $4 \pi$ geometry needs to be established.

\section{Acknowledgements}

These studies were supported by the BMBF of the FRG under contracts 06 DR $101 \mathrm{D}, 06 \mathrm{DR} 666 \mathrm{I}(4) /$ 1 , and were performed in cooperation with the GSI Darmstadt. 


\section{References}

1. Schädel, M., Brüchle, W., Dressler, R., Eichler, B., Gäggeler, H. W., Günther, R., Gregorich, K. E., Hoffman, D. C., Hübener, S., Jost, D. T., Kratz, J. V., Paulus, W., Schumann, D., Timokhin, S., Trautmann, N., Türler, A., Wirth, G., Yakushev, A.: Chemistry Gains a New Element: $Z=106$. Nature, 388, 55 (1997).

2. Vahle, A., Hübener, S., Eichler, B.: Thermochromatographic Studies of Oxide and Hydroxide Species of Molybdenum Model Experiments with Respect to the Physico-Chemical Characterization of Element 106. Radiochim. Acta 69, 233 (1995).

3. Vahle, A., Grantz, M., Hübener, S., Jost, D. T., Türler, A.: On-line Gas Chromatography of Short-lived Mo and W Isotopes in the $\mathrm{O}_{2}-\mathrm{H}_{2} \mathrm{O}_{(\mathrm{g})} / \mathrm{SiO}_{2(\mathrm{~s})}-$ System - Experiment and Simulation. Institute of Radiochemistry Annual Report 1997, FZR 218, p. 85 (1998).

4. Türler, A., Dressler, R., Eichler, B., Gäggeler, H. W., Jost, D. T., Schädel, M., Brüchle, W., Gregorich, K. E., Trautmann, N., Taut, S.: Decay Properties of ${ }^{265} \mathrm{Sg}(Z=106)$ and ${ }^{266} \mathrm{Sg}(Z=106)$. Phys. Rev. C 57, 1648 (1998).

5. Pershina, V.: Electronic Structure and Properties of the Transactinides and Their Compounds. Chem. Rev. 96, 1977 (1996).

6. Eichler, B.: Thermodynamische Zustandsfunktionen für die Transportreaktionen des Elements 106 im System Sauerstoff-Wasserdampf, Dresden 1992, unpublished.

7. Eichler, B.: Eigenschaften des Elementes 106 und ihre wechselseitigen Abhängigkeiten. Workshop ,Chemie der schwersten Elemente", 25.-27.05.1993, Solothurn.

8. Knacke, O., Kubaschewski, O., Hesselmann, K.: Thermochemical Properties of Inorganic Substances, Springer-Verlag, $2^{\text {nd }}$ Ed., Berlin (1991).

9. Glemser, O., Haeseler, R. v.: Über gasförmige Hydroxide des Molybdäns and Wolframs. Z. Anorg. Allg. Chemie 316, 168 (1962).

10. Glemser, O., Wendlandt, H. G.: Gaseous Hydroxides. Adv. Inorg. Chem. Radiochem. 5, 215 (1963).

11. Millner, T., Neugebauer, J.: Volatility of the Oxides of Tungsten and Molybdenum in the Presence of Water Vapour. Nature 163, 601 (1949).

12. Kilpatrick, M., Lott, S. K.: Reaction of Flowing Steam with Refractory Metals. III: Tungsten $\left(1000-1700^{\circ} \mathrm{C}\right)$. J. Electrochem. Soc. 113, 17 (1966).

13. Schäfer, H., Grofe, T., Trenkel, M.: The Chemical Transport of Molybdenum and Tungsten and of their Dioxides and Sulfides. J. Solid State Chem. 8, 14 (1973).

14. Kubaschewski, O., Alcock, C. B.: Metallurgical Thermochemistry, Pergamon Press, $5^{\text {th }}$ Ed., Oxford (1979).

15. Dellien, I., Hall, F. M., Hepler, L. G.: Chromium, Molybdenum, and Tungsten: Thermodynamic Properties, Chemical Equilibria and Standard Potentials. Chem. Rev. 76, 283 (1976).

16. Barin, J., Knacke, O.: Thermodynamic Properties of Inorganic Substances, Springer, Berlin (1973).

17. Chase, M. W., Davies, C. A., Downey, J. R., Frurip, D. J., McDonald, R. A., Syverud, A. N.: JANAF Thermochemical Tables, $3^{\text {rd }}$ Ed., J. Phys. Chem. Ref. Data 14, Suppl. 1 (1985).

18. Cordfunke, E. H. P., Konings, R. J. M.: Thermochemical Data for Reactor Materials and Fission Products. NorthHolland, Amsterdam (1990).

19. Bayar, B., Novgorodov, A. F., Vocilka, I., Zaitseva, N. G.: Fast Gas-Thermochromatographic Separation of Radioactive Elements. III. Production and Thermochromatographic Behaviour of Volatile Oxides and Hydroxides of Radioactive Tungsten. Radiochem. Radioanal. Letters 22, 53 (1975).
20. Becker, U.: Chromatographische Methoden zum Studium der chemischen Eigenschaften des Elements 106 im Vergleich zu den Homologen Mo, W and U. PhD Thesis, Universität Mainz 1994.

21. Eichler, B., Domanov, V.: Verflüchtigung von Radionukliden im Luftstrom und ihre Abscheidung im Temperaturgradientrohr. J. Radioanal. Chem. 28, 143 (1975).

22. De Boer, J. H.: The Dynamical Character of Adsorption, Clarendon Press, Oxford (1953).

23. Eichler, B., Zvara, I.: Evaluation of the Enthalpy of Adsorption from Thermochromatographical Data. Radiochim. Acta 30, 233 (1982).

24. Oppermann, H.: Sättigungsdruck und Bildungsenthalpie von $\mathrm{MoO}_{2} \mathrm{Br}_{2}$ und $\mathrm{MoO}_{2} \mathrm{Cl}_{2}$. Z. Anorg. Allg. Chem. 379, 262 (1970).

25. Oppermann, H.: Sättigungsdrucke, Bildungsenthalpien von $\mathrm{WOCl}_{4}$ und $\mathrm{WO}_{2} \mathrm{Cl}_{2}$ und das Zersetzungsgleichgewicht $2 \mathrm{WO}_{2} \mathrm{Cl}_{2}=\mathrm{WO}_{3}+\mathrm{WOCl}_{4 . \mathrm{g}}$. Z. Anorg. Allg. Chem. 383, 1 (1971).

26. Eichler, B.: Das Flüchtigkeitsverhalten von Transactiniden im Bereich um $Z=114$ (Voraussage). Kernenergie 19, 307 (1976).

27. Eichler, B., Gäggeler, H. W.: Prediction of Chemical Properties of Element 106. PSI Annual Report 1993, Labor für Radio- und Umweltchemie, p. 40.

28. Farber, M., Srivastava, R. D.: A Mass Spectrometric Investigation of Reactions involving Vanadium and Chromium with Potassium-Seeded $\mathrm{H}_{2} / \mathrm{O}_{2}$ Flames. Combustion and Flame 10, 43 (1973).

29. Leipnitz, E., Struppe, H. G.: Handbuch der Gaschromatographie. Verlag Chemie, Weinheim (1970).

30. Eichler, B., Zude, F., Fan, W., Trautmann, N., Herrmann, G.: Complex Transport Reactions in a Temperature Gradient Tube: Radiochemical Study of Volatilization and Deposition of Iridium Oxides and Hydroxides. Radiochim. Acta 61, 81 (1993).

31. Eichler, B.: The Behaviour of Radionuclides in Gas Adsorption Chromatographic Processes with Superimposed Chemical Reactions. Radiochim. Acta 72, 19 (1996).

32. Funke, H., Hübener, S., Roß, A., Eichler, B.: Contribution to the Evaluation of Thermochromatographic Experiments. Forschungszentrum Rossendorf, Institute of Radiochemistry, Annual Report 1993, FZR-43, p. 53 (1994).

33. Funke, H., Vahle, A., Hübener, S.: Contribution to the Evaluation of Thermochromatographic Studies of Tungsten. Forschungszentrum Rossendorf, Institute of Radiochemistry, Annual Report 1994, FZR-94, p. 85 (1995).

34. Zvara, I.: Simulation of Thermochromatographic Processes by the Monte Carlo Method. Radiochim. Acta 38, 95 (1985).

35. Vahle, A., Hübener, S., Dressler, R., Eichler, B., Türler, A.: Reaction Gas Chromatography of Oxide and Hydroxide Species of Molybdenum - Simulation and Experiment. Radiochim. Acta 78, 53 (1997).

36. Dressler, R., Türler, A., Jost, D. T., Piguet, D., Eichler, B., Gäggeler, H. W.: On-Line Gaschromatography of shortlived Tungsten Nuclides. PSI Annual Report 1994, Labor für Radio- und Umweltchemie, p. 45.

37. Türler, A. for a collaboration: First Thermochemical Property of Seaborgium Determined. PSI Annual Report 1996, Labor für Radio- und Umweltchemie, p. 29.

38. Vahle, A.: Hochtemperaturgaschromatographie mit Spurenmengen der Elemente der 6. Gruppe im $\mathrm{O}_{2}-\mathrm{H}_{2} \mathrm{O}_{(\mathrm{g})} / \mathrm{SiO}_{2(\mathrm{~s})}{ }^{-}$ System. PhD Thesis, TU Dresden 1996.

39. Türler, A.: Gas Phase Chemistry Experiments with Transactinide Elements. Radiochim. Acta 72, 7 (1996). 
